\title{
Local Acetaldehyde: Its Key Role in Alcohol-Related Oropharyngeal Cancer
}

\author{
Mikko Salaspuro \\ Research Unit on Acetaldehyde and Cancer, University of Helsinki, Biomedicum Helsinki, Helsinki, Finland
}

\section{Keywords}

Acetaldehyde · Alcohol · ALDH2 - Cancer · Oropharynx

\begin{abstract}
Background: Alcohol consumption and ethanol in alcoholic beverages are group 1 carcinogens, that is, carcinogenic to humans. However, ethanol itself is neither genotoxic nor mutagenic. Based on unique gene-epidemiologic and genebiochemical evidence, the first metabolite of ethanol oxidation - acetaldehyde $(\mathrm{ACH})$ - acts as a local carcinogen in the oropharynx. This review is focused on those facts, which highlight the importance of the oropharynx and local ACH in the pathogenesis of alcohol-related oropharyngeal cancer. Summary: The strongest evidence for the local carcinogenicity of $\mathrm{ACH}$ in man provides a point mutation in the aldehyde dehydrogenase 2 (ALDH2) gene, which has randomized millions of alcohol consumers to markedly increased $\mathrm{ACH}$ exposure via saliva. This novel human cancer model is associated with manifold risk for oropharyngeal cancer and most importantly it is free from confounding factors markedly hampering epidemiological studies on alcohol-related cancer. The oropharynx is an ideal target organ for the cancer risk assessment of $\mathrm{ACH}$. There is substantial epidemiological data on alcohol-related oropharyngeal cancer risk and also on salivary $\mathrm{ACH}$ concentrations among major risk groups for oropharyngeal cancer. Normal human saliva does
\end{abstract}

not contain measurable levels of $\mathrm{ACH}$. However, alcohol ingestion results within seconds in a concentration-dependent accumulation of $\mathrm{ACH}$ in saliva, which continues for up to $10-15 \mathrm{~min}$ after each sip of alcoholic beverage. This instant $\mathrm{ACH}$ exposure phase is followed by a long-term phase derived from ethanol diffused back to saliva from blood circulation. Microbes representing normal oral flora play a major role in local ACH formation from ethanol. In ALDH2-deficient subjects excess $\mathrm{ACH}$ during the long-term $\mathrm{ACH}$ exposure phase is most probably derived from salivary glands. Key Message: $A L D H 2$ gene mutation proves the causal relationship between local ACH exposure via saliva and oropharyngeal cancer and provides new means for the quantitative assessment of local ACH exposure in relation to oropharyngeal cancer risk. Instant ACH formation from ethanol represents approximately $70-100 \%$ of total local ACH exposure. Ethanol present in "non-alcoholic" beverages and food forms an epidemiological bias in studies on alcohol-related upper digestive tract cancer. Responses: One should quit smoking, adopt sensible drinking habits, and maintain good oral hygiene. Genetic risk groups could be screened and educated. Consumption of beverages and foodstuffs containing low ethanol levels as well as alcoholic beverages containing high ACH levels should be minimized. To that aim, labelling of alcohol and $\mathrm{ACH}$ concentrations of all beverages and foodstuffs should be mandatory.

(c) 2020 S. Karger AG, Basel 


\section{Introduction}

Strong genetic-epidemiologic and genetic-biochemical evidence supports the crucial role of locally formed acetaldehyde $(\mathrm{ACH})$ from ethanol as a major pathogenetic factor behind alcohol-related upper digestive tract cancer. Although the International Agency for Research on Cancer (IARC) classifies alcohol consumption and ethanol in alcoholic beverages as group 1 carcinogens to humans, an ethanol molecule in itself is neither genotoxic, mutagenic, nor carcinogenic. However, its first metabolite $\mathrm{ACH}$ is a group 1 carcinogen to humans when associated with the consumption of alcoholic beverages [1]. Group 1 classification especially concerns the upper digestive tract, where the causal relationship between alcoholic beverage consumption and cancer of the oral cavity, pharynx, and esophagus has been established.

A major part of ingested alcohol is metabolized in the liver via $\mathrm{ACH}$ to acetate, which is further oxidized in the peripheral tissues to carbon dioxide and water. It is less well recognized that hepatic cytoplasmic and mitochondrial aldehyde dehydrogenase (ALDH) enzymes break down ACH so efficiently that after a dose of alcohol neither peripheral nor hepatic venous blood contain measurable levels of $\mathrm{ACH}$ [2]. On the other hand, after a dose of alcohol, mutagenic ACH concentrations are found in the saliva and gastric juice of humans and in colonic contents of experimental animals. This locally formed $\mathrm{ACH}$ is by and large produced by microbes representing normal gastrointestinal flora $[3,4]$.

The local carcinogenic potential of $\mathrm{ACH}$ is supported by epidemiological findings indicating that alcohol-related cancer risk is increased mainly in those organs in which local ACH levels are elevated after alcohol administration. These organs include the oral cavity, pharynx, larynx, esophagus, stomach, large intestine, and cirrhotic liver. On the contrary, alcohol-related cancer risk is not increased in organs, which do not express elevated $\mathrm{ACH}$ levels in the presence of ethanol. Such organs are for instance the prostate, pancreas, lung, brain, kidney, bone, endocrine organs, and blood cells. The only exception is breast cancer, the incidence of which is dose-dependently associated with increased alcohol consumption. However, there is no evidence of locally elevated ACH levels in mammary glands in the presence of ethanol. It is generally agreed that the pathogenesis of alcohol-related breast cancer is still hypothetical.

\section{Unique Characteristics of ALDH2 Gene Mutation}

Finding a specific carcinogenic agent is a key factor in cancer prevention. To that aim a single point mutation in the $A L D H 2$ gene proves conclusively the causal role of lo- cal $\mathrm{ACH}$, especially in alcohol-related upper digestive tract and particularly in oropharyngeal cancer $[3,5]$. Mutation results in deficient activity of the main $\mathrm{ACH}$ metabolizing low $\mathrm{K}_{\mathrm{M}}$ mitochondrial ALDH2 enzyme. As a result, ALDH2-deficients are exposed via saliva to about 2 and via gastric juice to 5-6 times higher local ACH concentrations than ALDH2-actives each time they drink alcohol $[6,7]$. The enhanced ACH exposure in alcohol drinkers is associated with markedly and dose-dependently increased risk for oral, pharyngeal, esophageal, and gastric cancer $[6,8,9]$.

The incidence of $A L D H 2$ gene mutation (1:13) is more frequent than that of familial hypercholesterolemia (1: 500). Today its carrier frequency is about 600 million people of East-Asian descent. Because this human ACH exposure model is randomized by nature, it lacks the bias caused by confounding factors hampering most epidemiological studies on alcohol-related cancer. Smoking, diet, under reporting, drinking habits, use of different types of alcoholic beverages, oral hygiene, HPV, and BMI can be assumed to be evenly distributed among ALDH2deficient and ALDH2-active alcohol drinkers. Any other group 1 carcinogen $(n=120)$ has equally strong geneepidemiologic and gene-biochemical evidence for its carcinogenicity in humans. With regard to $\mathrm{ACH}$, data based on animal toxicology is problematic due to poor study quality, problems in animal models, and relevance of the endpoint (cancer linkage) in translation to humans [6]. Consequently, animal and DNA-based carcinogenicity data on $\mathrm{ACH}$ can be considered to be of secondary importance as compared to the specific human data provided by the single point mutation in the $A L D H 2$ gene.

\section{Oropharynx and Salivary ACH}

Oropharynx provides an ideal target organ for the quantitative estimation of local $\mathrm{ACH}$ exposure via saliva in humans for 3 reasons: (1) oropharyngeal mucosa lacks low $\mathrm{K}_{\mathrm{M}} \mathrm{ALDH}$-enzymes and is therefore unable to eliminate from either ethanol-formed or free $\mathrm{ACH}$ present in many alcoholic beverages [10]; (2) oral microbes have a very low or no ALDH activity, and therefore their capacity to eliminate local ACH is minimal [11]; (3) there is adequate research data on salivary ACH levels in the presence of ethanol and also on alcohol-related oropharyngeal cancer risk in ALDH2-active and ALDH2-deficient alcohol drinkers [6].

Instant and Long-Term Local ACH Exposure via Saliva Oropharyngeal mucosa is exposed to $\mathrm{ACH}$ via saliva in 2 phases (Fig. 1). The most prominent local exposure takes place immediately after sipping alcohol $[3,12,13]$. Ethanol is distributed to oral mucosal surfaces and saliva 
Fig. 1. Instant and long-term salivary $\mathrm{ACH}$ formation from ethanol after a dose of alcohol. Gray columns, microbial ACH formation; black column, excess $\mathrm{ACH}$ in ALDH2-deficients compared to that of ALDH2-actives.

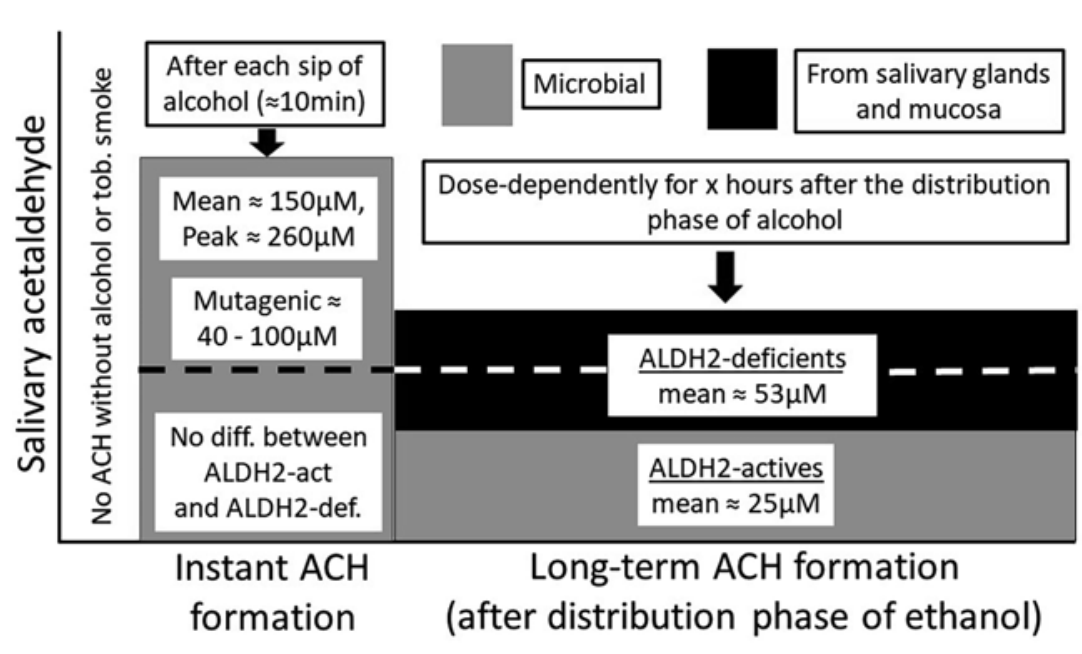

Table 1. Approximation of instant local ACH exposure via saliva after one dose of $40 \%$ alcohol ingested in 3 sips at 5-min intervals in relation to the risk for oropharyngeal cancer

\begin{tabular}{lllll}
\hline $\begin{array}{l}\text { Exposure model } \\
\text { to local ACH }\end{array}$ & $\begin{array}{l}\text { Salivary } \\
\mathrm{ACH}, \mathrm{mg} / \mathrm{L}\end{array}$ & $\begin{array}{l}\text { Exposure } \\
\text { time, min }\end{array}$ & $\begin{array}{l}\text { AUC, mg/L } \times \\
\text { min/day }\end{array}$ & $\begin{array}{l}\text { OR for oropharyngeal } \\
\text { cancer [17, 18] }\end{array}$ \\
\hline $\begin{array}{l}\text { Instant } \\
\quad 3 \times \text { first } 5 \text { min } \\
\quad \begin{array}{l}1 \times \text { next } 5 \text { min } \\
\text { Instant total, } n(\%)\end{array}\end{array}$ & 6.2 & 15 & 93 & \\
$\begin{array}{l}\text { Long term } \\
\quad 20-80 \text { min }\end{array}$ & 0.4 & 5 & $115(68)$ & \\
\hline Total, $n(\%)$ & 80 & $53(32)$ & $1.17-1.21$ \\
\hline
\end{tabular}

Adapted from Nieminen and Salaspuro [3] and Linderborg et al. [12].

instantly after each sip of an alcoholic beverage. Five milliliters of $40 \%$ ethanol results in peak salivary ethanol levels of $900 \mathrm{~mm}(4.3 \%)$ within $30 \mathrm{~s}$ and, stay elevated $>21$ $\mathrm{mM}(1 \%)$ for at least $10 \mathrm{~min}[12,13]$. This is associated with instant and mainly microbial ACH formation from ethanol in saliva in mutagenic concentrations (mean 150 $\mu \mathrm{M}$, peak $260 \mu \mathrm{M})$, which lasts up to $15-20 \mathrm{~min}[12,13]$. The ALDH2 genotype has no effect on the instant $\mathrm{ACH}$ exposure via saliva, indicating that neither mucosal nor salivary gland ALDH2 enzymes play any significant role in this metabolic process [13].

Long-term exposure represents $\mathrm{ACH}$ formed from ethanol that is diffused back to saliva from blood after the distribution phase of alcohol to the water phase of the human body, that is, within about 30 min after the last sip of alcohol (Fig. 1). Depending on the total amount of alcohol ingested, the long-term phase lasts for hours, that is, for as long as alcohol stays in the blood circulation and saliva [14]. In ALDH2-actives, the mean salivary ACH concentration during the long-term phase is about $25 \mu \mathrm{M}$, but depending on the individual characteristics of oral microflora the peak levels may go up to over $100 \mu \mathrm{M}$ [14]. In contrast to instant $\mathrm{ACH}$ exposure, the mean salivary $\mathrm{ACH}$ during the long-term phase is about double (approx. $53 \mu \mathrm{M})$ in ALDH2-deficients compared to ALDH2actives (Fig. 1) $[6,15]$. The additional ACH during the long-term phase of $\mathrm{ACH}$ exposure is presumably derived to the oral cavity from the salivary glands $[15,16]$.

\section{Estimation of Local ACH Exposure via Saliva after \\ One Dose of Alcohol}

Monitoring salivary ACH levels after drinking alcohol provides unique means for the quantitative approximation of $\mathrm{ACH}$ exposure via saliva in the oropharynx. One dose of alcohol ( $10 \mathrm{~g}$ of ethanol) daily is associated with a significant risk (RR 1.17-1.21; approx. 20\% increase) for oropharyngeal cancer $[17,18]$. After one dose of alcohol the total local ACH exposure via saliva can be calculated 
Table 2. Approximation of the excess long-term ACH exposure via saliva of ALDH2-deficient moderate and heavy drinkers as compared to that of ALDH2-actives and in relation to the risk for oropharyngeal cancer

\begin{tabular}{lllll}
\hline Exposure model & $\begin{array}{l}\text { Excess salivary } \\
\mathrm{ACH}, \mathrm{mg} / \mathrm{L}^{1}\end{array}$ & $\begin{array}{l}\text { Exposure } \\
\text { time, } \mathrm{min}^{2}\end{array}$ & $\begin{array}{l}\text { AUC, mg/L } \\
\times \text { min/day }\end{array}$ & $\begin{array}{l}\text { OR for oropharyngeal } \\
\text { cancer [8, 20] }\end{array}$ \\
\hline $\begin{array}{l}\text { ALDH2-deficiency model } \\
\quad \text { Moderate drinkers (33 g/ethanol/day) }\end{array}$ & 1.1 & 283 & 311 & $1.7-2.6$ \\
$\quad$ Heavy drinkers (77 g/ethanol/day) & 1.1 & 660 & 726 & $3.6-7.3$ \\
\hline
\end{tabular}

Adapted from Nieminen and Salaspuro [3] and Lachenmeier and Salaspuro [6].

${ }^{1}$ Long-term excess ACH exposure via saliva (salivary ACH $[\mathrm{mg} / \mathrm{L}]$ in ALDH2-deficients minus that in ALDH2-actives).

${ }^{2}$ Exposure time to local ACH via saliva is based on the elimination rate of ethanol $(7 \mathrm{~g} / \mathrm{h})$.

Fig. 2. Effect of alcohol on the approximated local ACH exposure $(\mathrm{mg} / \mathrm{L} \times \mathrm{min} /$ day $)$ in relation to increased oropharyngeal cancer risk (OR/RR). $\mathrm{ACH}^{1}$ (white circle), mean instant $\mathrm{ACH}$ exposure via saliva after one dose of $40 \%$ alcohol (Table 1 ); excess $\mathrm{ACH}^{2}$ (gray and black circles); mean longterm exposure to excess salivary $\mathrm{ACH}$ in ALDH2-deficients compared to that of ALDH2-actives (Table 2).

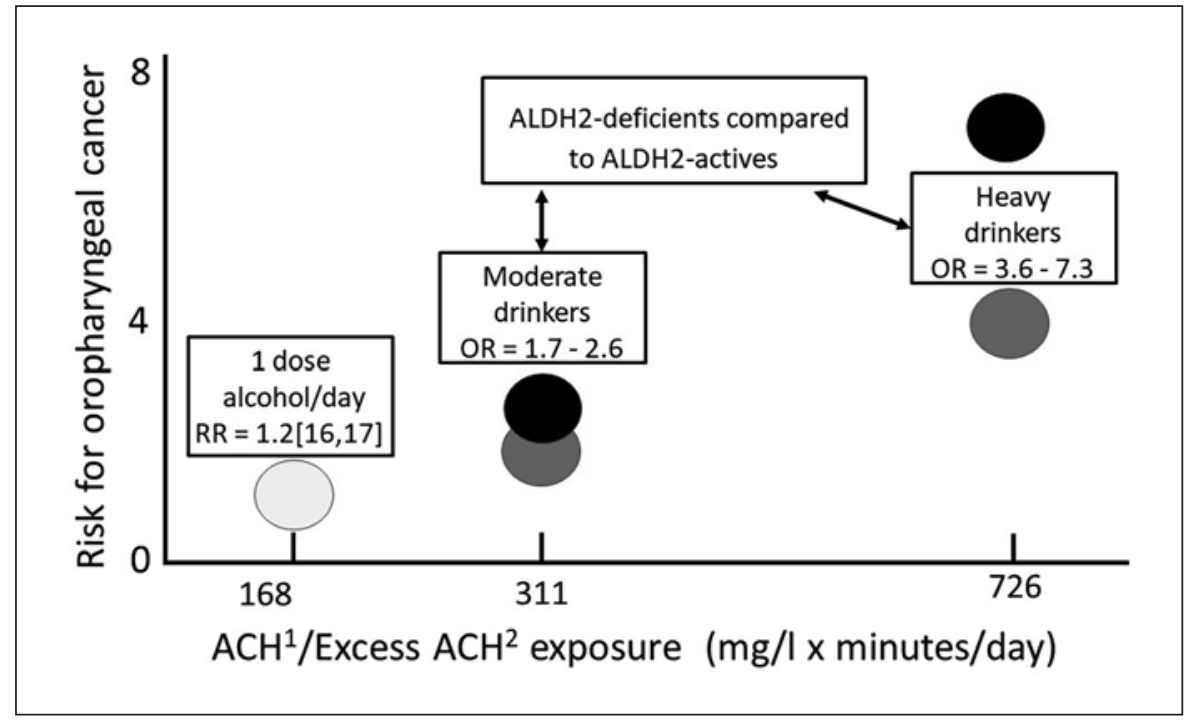

by approximating the area under the curve during the instant and long-term phase of ACH exposure (Table 1). Without the presence of alcohol or tobacco smoke, salivary $\mathrm{ACH}$ levels are under the detection limit $[14,19]$. If one dose of strong alcohol is assumed to be ingested in 3 sips at 5-min intervals, the mean instant $\mathrm{ACH}$ exposure represents about $70 \%$ of the total $\mathrm{ACH}$ exposure (Table 1). High concentrations of free $\mathrm{ACH}$ present in some alcoholic beverages results in a short, 1- to 2-min peak (up to approx. $1 \mathrm{mM}$ ) in the salivary $\mathrm{ACH}$ concentration, which can be calculated to represent a maximum of $10 \%$ of the total local ACH exposure $[3,12]$.

\section{Estimation of Excess Local ACH Exposure via Saliva} in ALDH2-Deficients Compared to ALDH2-Actives

According to one meta-analysis and one well-performed study, ALDH2 deficiency is associated with a 1.68- to 2.61-fold oropharyngeal cancer risk in moderate drinkers and 3.57- to 7.28-fold risk in heavy drinkers $[8,20]$. Based on 5 studies with consistent findings, the long-term salivary $\mathrm{ACH}$ concentration has a mean increase of 2.1-fold in ALDH2-deficient subjects compared with ALDH2-actives for as long as alcohol stays in the human body after its intake [6]. On the basis of the normal alcohol elimination rate $(7 \mathrm{~g} / \mathrm{h})$, the longterm exposure time to an elevated $\mathrm{ACH}$ level in saliva is $283 \mathrm{~min}$ in moderate and $660 \mathrm{~min}$ in heavy drinkers. By using these numbers, the total excess $\mathrm{ACH}$ exposure of the oropharyngeal mucosa of ALDH2-deficients compared to that of ALDH2-actives can be approximated as described in Table 2. In summary, oropharyngeal cancer risk derived from epidemiological studies appears to correlate dose dependently with the local $\mathrm{ACH}$ exposure caused by one dose of alcohol per day and also with the excess local $\mathrm{ACH}$ exposure due to the deficient ALDH2 enzyme (Fig. 2). This gene-epidemiologic and gene-biochemical evidence proves conclusively the causal role of local ACH in the pathogenesis of oropharyngeal cancer. Furthermore, the model provides a unique way for the quantitative estimation of local $\mathrm{ACH}$ exposure in the oropharynx in relation to alcohol-related cancer risk in alcohol drinkers. 
Table 3. Major factors affecting salivary ACH concentrations

\begin{tabular}{|c|c|c|}
\hline Factor & Effect & Implications \\
\hline $\begin{array}{l}\text { Individual characteristics of oral } \\
\text { microbes }\end{array}$ & $\begin{array}{l}30 \text {-fold range in the ability of oral bacteria } \\
\text { to produce } \mathrm{ACH} \text { from ethanol in vitro }\end{array}$ & $\begin{array}{l}\text { High variety in salivary ACH levels after } \\
\text { alcohol ingestion }\end{array}$ \\
\hline $\begin{array}{l}\text { High variation in } K_{M} \text { values of } \\
\text { microbial ADHs }\end{array}$ & $\begin{array}{l}\text { Number of microbes producing } \mathrm{ACH} \text { from } \\
\text { ethanol increases in rising salivary ethanol } \\
\text { concentrations }\end{array}$ & $\begin{array}{l}\text { High salivary ACH levels (up to } 260 \mu \mathrm{M} \text { ) } \\
\text { during the instant phase of ACH exposure }\end{array}$ \\
\hline Alcohol concentration & $\begin{array}{l}\text { Higher salivary ethanol concentration } \\
\text { associates with higher ACH formation both } \\
\text { in vitro and in vivo }\end{array}$ & $\begin{array}{l}\text { High salivary } \mathrm{ACH} \text { concentrations especially } \\
\text { during the instant phase of } \mathrm{ACH} \text { exposure }\end{array}$ \\
\hline Smoking & $\begin{array}{l}\text { ACH of tobacco smoke dissolves into saliva } \\
\text { during active smoking }\end{array}$ & \multirow{2}{*}{$\begin{array}{l}\text { Results in about } 7 \text {-fold increase in total } \mathrm{ACH} \\
\text { exposure via saliva and explains, together } \\
\text { with microbial changes, the synergistic effect } \\
\text { of smoking and drinking on oropharyngeal } \\
\text { cancer risk }\end{array}$} \\
\hline Smoking and heavy drinking & $\begin{array}{l}\text { Both increase microbial ACH production } \\
\text { in saliva by } 50 \% \text {; when combined the } \\
\text { increase is } 100 \%\end{array}$ & \\
\hline Poor oral hygiene & $\begin{array}{l}\text { Increases in vitro and in vivo salivary } \mathrm{ACH} \\
\text { production from ethanol }\end{array}$ & $\begin{array}{l}\text { Poor oral hygiene is a risk factor for } \\
\text { oropharyngeal cancer }\end{array}$ \\
\hline $\begin{array}{l}\text { High ACH concentration in } \\
\text { alcoholic beverages }\end{array}$ & $\begin{array}{l}\text { Results in a short 30-s - 2-min peak in } \\
\text { salivary ACH }\end{array}$ & $\begin{array}{l}\text { Depending on } \mathrm{ACH} \text { of beverage and number } \\
\text { of sips may represent } 0-10 \% \text { of total } \mathrm{ACH} \\
\text { exposure }\end{array}$ \\
\hline ALDH2 deficiency & $\begin{array}{l}\text { ALDH2 deficiency results in } 2.1 \text {-fold } \\
\text { local long-term ACH exposure after } \\
\text { alcohol drinking as compared to that of } \\
\text { ALDH2-actives }\end{array}$ & $\begin{array}{l}\text { Provides a unique human model for local } \\
\text { ACH exposure via saliva }\end{array}$ \\
\hline
\end{tabular}

Dominant Role of Oral Microbes in Salivary ACH

Production from Ethanol

Convincing evidence supports the major role of oral microbes in the formation of salivary $\mathrm{ACH}$ from ethanol [3]. The oropharyngeal microbiome consists of over 700 bacterial species and a rich fungal flora. Many microbes representing normal oral flora are high $\mathrm{ACH}$ producers. These include, for instance, many Streptococcus and Neisseria genuses, some Candida albicans and some non- $C$. albicans species. Characteristically, oral microbes represent a variety of alcohol dehydrogenase $(\mathrm{ADH})$ enzymes, which under aerobic conditions are able to produce marked amounts of $\mathrm{ACH}$ from ethanol both in vitro and in vivo. On the contrary, oral microbes show no or very low ALDH activity [11]. These microbial characteristics result in the linear accumulation of $\mathrm{ACH}$ in mutagenic concentrations in saliva in the presence of increasing levels of ethanol. The key role of normal oral microflora in salivary ACH production from ethanol is supported by the fact that $\mathrm{ACH}$ formation is reduced by half after a 3-day use of chlorhexidine containing antiseptic mouthwash [14]. This associates with a significant decrease in baseline aerobic and anaerobic bacterial counts of saliva.

4-methylpyrazole (4-MP) is a potent inhibitor of human ADH enzyme. However, much higher 4-MP concentrations are required for the inhibition of microbial
ADH enzymes in saliva [14]. A single dose of 4-MP before ethanol ingestion reduces the ethanol elimination rate, the flushing reaction, and both blood and salivary $\mathrm{ACH}$ levels in ALDH2-deficient subjects, but not in subjects with the normal ALDH2 genotype [16]. These results suggest that the role of oral mucosal and glandular ADHs in salivary $\mathrm{ACH}$ production from ethanol is minimal in subjects with normally active ALDH2 enzyme and that among them salivary ACH production is mainly of microbial origin. On the other hand, the findings support the conclusion that the excess long-term $\mathrm{ACH}$ exposure in ALDH2-deficient alcohol drinkers is derived from salivary glands $[15,16]$.

\section{Major Factors Affecting Salivary ACH Levels}

Individual characteristics of thousands of different microbial strains play a key role in the regulation of salivary $\mathrm{ACH}$ concentrations in the presence of ethanol (Table 3). Based on 100 saliva samples of healthy volunteers, a 30 -fold range in the ability of oral microbes to produce $\mathrm{ACH}$ from ethanol has been demonstrated [21]. This explains at least in part the high individual variation in salivary ACH concentrations after alcohol ingestion. Particularly high salivary $\mathrm{ACH}$ levels are found immediately after sipping alcohol, that is, during the instant phase of local $\mathrm{ACH}$ exposure, when salivary ethanol levels are highest (Fig. 1). This can 
also be explained to be at least in part secondary to the high variation in $\mathrm{K}_{\mathrm{M}}$ values of different microbial $\mathrm{ADH}$ enzymes. Consequently, the number of microbes producing $\mathrm{ACH}$ from ethanol increases in rising salivary ethanol concentrations. A higher salivary ethanol concentration associated with higher $\mathrm{ACH}$ formation in saliva has been demonstrated both in vitro and in vivo [7, 12-14].

Tobacco and alcohol have a synergistic effect on the risk for oropharyngeal cancer [22]. $\mathrm{ACH}$ of tobacco smoke dissolves into saliva during active smoking, resulting in a mean salivary ACH concentration of $260 \mu \mathrm{M}$ [19]. Furthermore, chronic smoking and heavy drinking modify the oral microflora to produce higher $\mathrm{ACH}$ levels from ethanol in vivo and in vitro $[19,23]$. Consequently, smokers with active smoking during ethanol challenge are exposed to 7 times higher $\mathrm{ACH}$ levels via saliva than nonsmokers [19]. Poor oral hygiene is an independent risk factor for oropharyngeal cancer. On the other hand, it significantly increases in vitro salivary $\mathrm{ACH}$ production from ethanol [24]. Some strong fruit-based alcoholic beverages, such as calvados and grappa, may contain very high ACH concentrations. However, due to the fast elimination of $\mathrm{ACH}$ immediately after sipping this type of beverage, the additional free $\mathrm{ACH}$ of the drink contributes only marginally (max. 10\%) to the total ACH exposure via saliva $[3,12]$. ALDH2 deficiency results in a 2.1fold local long-term $\mathrm{ACH}$ exposure after drinking alcohol as compared to that of ALDH2-actives. Therefore, the single point mutation in the $A L D H 2$ gene provides a unique human model for local $\mathrm{ACH}$ exposure via saliva.

\section{Low Alcohol Levels in Food and Beverages: Significant Epidemiological Bias}

Microbial fermentation has been used for thousands of years for food preservation. Although lactic acid is the most common end product of food fermentation processes, many microbes are able to also produce ethanol and $\mathrm{ACH}$ under prevailing anaerobic conditions. Ethanol concentration levels ranging from $0.5 \%$ to $2.5 \%$ or even higher have been measured. These products include, for instance, homemade mead and beer, kefir, mursik milk, soy sauce, kimchi, pickled food, and vinegar [25-28]. Alcohol is often also added to marinades, fondues, salads, and sushi, but the ethanol concentration of the end product served is not known. Furthermore, it is poorly recognized that alcohol is not totally evaporated during cooking. Depending on the cooking procedure, alcohol concentrations ranging from 0.06 to $4.21 \%$ can still be measured after boiling [29].

The evidence on the carcinogenicity of alcohol and ACH in the oropharynx has so far been based on epidemiological studies in which alcohol consumption has been assessed by various types of questionnaires including only official alcoholic beverages (wine, beer, spirits) containing $3-50 \%$ ethanol. However, there is no systematic information on the ethanol and $\mathrm{ACH}$ concentrations of various widely used food products produced or preserved by fermentation. The same also concerns beverages containing lower concentrations of ethanol than official alcoholic drinks. Neither is it known how much and how often these types of foodstuffs or beverages have been used. This so far unknown part of local exposure of the oropharynx and other parts of the upper digestive tract to $\mathrm{ACH}$ derived from microbial oxidation of ethanol forms an obvious bias in alcohol-related upper GI tract cancer epidemiology.

\section{Conclusions}

Normal human saliva does not contain measurable levels of $\mathrm{ACH}$. However, alcohol ingestion results within seconds in a concentration-dependent accumulation of $\mathrm{ACH}$ in saliva, which continues up to 10-15 min after each sip of alcoholic beverage. This instant $\mathrm{ACH}$ exposure phase is followed by a long-term phase derived from alcohol diffused back to saliva from blood circulation. Microbes representing normal oral flora play a major role in salivary $\mathrm{ACH}$ formation from ethanol. The carcinogenicity of local $\mathrm{ACH}$ is based on a unique gene-epidemiologic and gene-biochemical human model concerning millions of East-Asian alcohol drinkers. A single point mutation in the $A L D H 2$ gene results in the doubling of local $\mathrm{ACH}$ exposure via saliva during the long-term phase of $\mathrm{ACH}$ exposure after drinking alcohol, which associates with dosedependently increasing oropharyngeal cancer risk. This provides conclusive evidence for the causal relationship between local $\mathrm{ACH}$ exposure and oropharyngeal cancer. It should be noted that the instant microbial ethanol metabolism results in mutagenic $\mathrm{ACH}$ concentrations in saliva also in lower ethanol concentrations ranging from $0.5 \%$ to $2.5 \%$, i.e., in those levels that are commonly measured in many food products and beverages produced by fermentation. Therefore, ethanol present in many "lowalcoholic beverages" and foods forms an unrecognized bias in upper digestive tract cancer epidemiology.

\section{Statement of Ethics}

No ethical considerations are relevant to this review article.

\section{Disclosure Statement}

The author has no conflicts of interest to declare.

\section{Funding Sources}

There are no funding sources to declare. 


\section{References}

1 IARC Working Group on the Evaluation of Carcinogenic Risks to Humans. Consumption of alcoholic beverages, vol. 100E. IARC Monogr Eval Carcinog Risks Hum; 2012. pp. 373-499.

2 Nuutinen HU, Salaspuro MP, Valle M, Lindros KO. Blood acetaldehyde concentration gradient between hepatic and antecubital venous blood in ethanol-intoxicated alcoholics and controls. Eur J Clin Invest. 1984 Aug; 14(4):306-11.

3 Nieminen MT, Salaspuro M. Local acetaldehyde - an essential role in alcohol-related upper gastrointestinal tract carcinogenesis. Cancers. 2018 Jan;10(1):1-23.

4 Jokelainen K, Matysiak-Budnik T, Mäkisalo H, Höckerstedt K, Salaspuro M. High intracolonic acetaldehyde values produced by a bacteriocolonic pathway for ethanol oxidation in piglets. Gut. 1996 Jul;39(1):100-4.

5 Salaspuro M. Key role of local acetaldehyde in upper GI tract carcinogenesis. Best Pract Res Clin Gastroenterol. 2017 Oct;31(5):491-9.

6 Lachenmeier DW, Salaspuro M. ALDH2-deficiency as genetic epidemiologic and biochemical model for the carcinogenicity of acetaldehyde. Regul Toxicol Pharmacol. 2017 Jun;86:128-36.

7 Maejima R, Iijima K, Kaihovaara P, Hatta W, Koike T, Imatani A, et al. Effects of ALDH2 genotype, PPI treatment and L-cysteine on carcinogenic acetaldehyde in gastric juice and saliva after intragastric alcohol administration. PLoS One. 2015 Apr;10(4):e0120397.

8 Boccia S, Hashibe M, Gallì P, De Feo E, Asakage T, Hashimoto T, et al. Aldehyde dehydrogenase 2 and head and neck cancer: a meta-analysis implementing a Mendelian randomization approach. Cancer Epidemiol Biomarkers Prev. 2009 Jan;18(1):248-54.

9 Matsuo K, Oze I, Hosono S, Ito H, Watanabe $\mathrm{M}$, Ishioka $\mathrm{K}$, et al. The aldehyde dehydrogenase 2 (ALDH2) Glu504Lys polymorphism interacts with alcohol drinking in the risk of stomach cancer. Carcinogenesis. 2013 Jul; 34(7):1510-5.

10 Dong YJ, Peng TK, Yin SJ. Expression and activities of class IV alcohol dehydrogenase and class III aldehyde dehydrogenase in human mouth. Alcohol. 1996 May-Jun;13(3):257-62.
11 Pavlova SI, Jin L, Gasparovich SR, Tao L. Multiple alcohol dehydrogenases but no functional acetaldehyde dehydrogenase causing excessive acetaldehyde production from ethanol by oral streptococci. Microbiology. 2013 Jul; 159(Pt 7):1437-46

12 Linderborg K, Salaspuro M, Väkeväinen S. A single sip of a strong alcoholic beverage causes exposure to carcinogenic concentrations of acetaldehyde in the oral cavity. Food Chem Toxicol. 2011 Sep;49(9):2103-6.

13 Helminen A, Väkeväinen S, Salaspuro M. ALDH2 genotype has no effect on salivary acetaldehyde without the presence of ethanol in the systemic circulation. PLoS One. 2013 Sep; 8(9):e74418

14 Homann N, Jousimies-Somer H, Jokelainen K, Heine R, Salaspuro M. High acetaldehyde levels in saliva after ethanol consumption: methodological aspects and pathogenetic implications. Carcinogenesis. 1997 Sep;18(9):1739-43.

15 Väkeväinen S, Tillonen J, Agarwal DP, Srivastava N, Salaspuro M. High salivary acetaldehyde after a moderate dose of alcohol in ALDH2-deficient subjects: strong evidence for the local carcinogenic action of acetaldehyde. Alcohol Clin Exp Res. 2000 Jun;24(6):873-7.

16 Väkeväinen S, Tillonen J, Salaspuro $M$. 4-Methylpyrazole decreases salivary acetaldehyde levels in aldh2-deficient subjects but not in subjects with normal ALDH2. Alcohol Clin Exp Res. 2001 Jun;25(6):829-34

17 Tramacere I, Negri E, Bagnardi V, Garavello W, Rota M, Scotti L, et al. A meta-analysis of alcohol drinking and oral and pharyngeal cancers. Part 1: overall results and dose-risk relation. Oral Oncol. 2010 Jul;46(7):497-503.

18 Bagnardi V, Rota M, Botteri E, Tramacere I, Islami F, Fedirko V, et al. Light alcohol drinking and cancer: a meta-analysis. Ann Oncol. 2013 Feb;24(2):301-8.

19 Salaspuro V, Salaspuro M. Synergistic effect of alcohol drinking and smoking on in vivo acetaldehyde concentration in saliva. Int $\mathrm{J}$ Cancer. 2004 Sep;111(4):480-3.

20 Tsai ST, Wong TY, Ou CY, Fang SY, Chen $\mathrm{KC}$, Hsiao JR, et al. The interplay between alcohol consumption, oral hygiene, ALDH2 and $\mathrm{ADH} 1 \mathrm{~B}$ in the risk of head and neck cancer. Int J Cancer. 2014 Nov;135(10):2424-36.
21 Yokoyama S, Takeuchi K, Shibata Y, Kageyama S, Matsumi R, Takeshita T, et al. Characterization of oral microbiota and acetaldehyde production. J Oral Microbiol. 2018 Jul; 10(1):1492316

22 Mello FW, Melo G, Pasetto JJ, Silva CA, Warnakulasuriya S, Rivero ER. The synergistic effect of tobacco and alcohol consumption on oral squamous cell carcinoma: a systematic review and meta-analysis. Clin Oral Investig. 2019 Jul;23(7):2849-59.

23 Homann N, Tillonen J, Meurman JH, Rintamäki H, Lindqvist C, Rautio M, et al. Increased salivary acetaldehyde levels in heavy drinkers and smokers: a microbiological approach to oral cavity cancer. Carcinogenesis. 2000 Apr;21(4):663-8.

24 Homann N, Tillonen J, Rintamäki H, Salaspuro M, Lindqvist C, Meurman JH. Poor dental status increases acetaldehyde production from ethanol in saliva: a possible link to increased oral cancer risk among heavy drinkers. Oral Oncol. 2001 Feb;37(2):153-8.

25 Nieminen MT, Novak-Frazer L, Collins R, Dawsey SP, Dawsey SM, Abnet CC, et al. Alcohol and acetaldehyde in African fermented milk mursik-a possible etiologic factor for high incidence of esophageal cancer in western Kenya. Cancer Epidemiol Biomarkers Prev. 2013 Jan;22(1):69-75.

26 Park SW, Lee SJ, Sim YS, Choi JY, Park EY, Noh BS. Analysis of ethanol in soy sauce using electronic nose for halal food certification. Food Sci Biotechnol. 2017 Apr;26(2):311-7.

27 Güzel-Seydim ZB, Seydim AC, Greene AK, Bodine AB. Determination of organic acids and volatile flavor substances in kefir during fermentation. J Food Compos Anal. 2000; 13(1):35-43.

28 Jeong SH, Lee SH, Jung JY, Choi EJ, Jeon CO. Microbial succession and metabolite changes during long-term storage of Kimchi. J Food Sci. 2013 May;78(5):M763-9.

29 Augustin J, Augustin E, Cutrufelli RL, Hagen SR, Teitzel C. Alcohol retention in food preparation. J Am Diet Assoc. 1992 Apr;92(4): 486-8. 